\title{
Floating ability and drug release evaluation of gastroretentive microparticles system containing metronidazole obtained by spray drying
}

\author{
Laís Nohemann, Marina Penteado de Almeida, Priscileila Colerato Ferrari*
}

Department of Pharmaceutical Sciences, State University of Ponta Grossa, Ponta Grossa, Paraná, Brazil

\begin{abstract}
Gastroretentive floating microparticles were developed and evaluated for the controlled metronidazole delivery for treatment of gastric disease. Floating microparticles, varying in proportions of chitosan and hydroxypropyl methylcellulose or ethylcellulose, were obtained by spray drying. Floating microparticles were characterized by physicochemical and in vitro studies, according to their floating ability and drug delivery. Microparticles presented mean diameter from 1.05 to $2.20 \mu \mathrm{m}$. The infrared spectroscopy confirmed the drug encapsulation and showed no chemical linkage between microparticles components. $\mathrm{X}$-ray diffraction showed changes in the drug`s solid state, from crystalline to amorphous, indicating partial drug encapsulation, due to the presence of some crystalline peaks of metronidazole in microparticles. All microparticles floated immediately in contact of simulated gastric fluid and both floating and drug release profiles were dependent of microparticles composition. Microparticles samples constituted by chitosan and hydroxypropyl methylcellulose revealed the best relationship between floating duration and drug release, remaining floating during the occurrence of the drug release, ideal condition for the floating gastroretentive systems.
\end{abstract}

Uniterms: Floating microparticle. Chitosan. Ethylcellulose. Hydroxypropyl methylcellulose. Controlled drug delivery.

\section{INTRODUCTION}

Gastroretentive systems have received significant interest in the past few decades, because they are able to sustain the drug release and to prolong the presence of the dosage form within the gastrointestinal tract until all the drug is completely released (Prajapati, Patel, Patel, 2008; Rapolu et al., 2012). Besides being able to continually and sustainably deliver drugs to the small intestinal absorption window, the improvements provided from gastroretentive systems include achieving a greater and prolonged therapeutic effect and thus reducing the frequency of administration periods, and providing a more effective treatment of local stomach disorders (Chen et al., 2010). Thereby, various approaches, such as floating, bioadhesive and swelling and expanding systems have been developed to increase the gastric retention time of dosage forms

\footnotetext{
*Correspondence: P. C. Ferrari. Departamento de Ciências Farmacêuticas. Universidade Estadual de Ponta Grossa. Avenida General Carlos Cavalcanti, 4748, 84030-900 - Uvaranas - Ponta Grossa, PR, Brazil. Tel. 55-42-3220 3782. E-mail: priscileila@hotmail.com / pcferrari@uepg.br
}

(Rajab et al., 2014; Ferrari et al., 2014; Lemieux, Gosselin, Mateescu, 2015; Priyadarshini et al., 2016).

A floating drug delivery system is of particular interest for drugs, which have a specific stomach action. Metronidazole (MT; 2-methyl-5-nitroimidazole-1-ethanol; Figure 1) is a drug used for the treatment and prevention of anaerobic microorganism and protozoa infections. MT is an active adjunct in treatment of Helicobacter pylori (Prasanthi et al., 2011; Emara et al., 2014). It is classified as Class I by Biopharmaceutical Classification System, has $\mathrm{pH}$ independent activity, and it is mainly absorbed in the stomach (Krishnaiah et al., 2003; Abou Youssef et al., 2015).

H. pylori is a gram-negative bacterium that causes infection of the upper gastrointestinal tract (Guimarães,<smiles>Cc1ncc([N+](=O)[O-])n1CCO</smiles>

FIGURE 1 - Chemical structure of metronidazole. 
Corvelo, Barile, 2008). This infection induces a persistent inflammation of the gastric mucosa with different types of lesions, such as chronic gastritis, peptic ulcer and gastric cancer. The determinants of these outcomes are the intensity and distribution of inflammation in the gastric mucosa and the gastritis induced by $H$. pylori is one of the most common infections in humans, affecting over $50 \%$ of the world population, reaching up to $90 \%$ of infected individuals in developing countries (Malfertheiner et al., 2012; Garcia et al., 2014; Payão, Rasmussen, 2016).

Microparticles in oral multiparticulate drug delivery system tend to be dispersed in regions of the gastrointestinal tract ensuring a more reliable and reproducible release profile and more uniform drug absorption (Asghar, Chandran 2006). Floating microparticles for the treatment of $H$. pylori allow the buoyancy of dosage form in the gastric fluid providing adequate prolongation of drug release near to the ecological niche of the bacterium (Abou Youssef et al., 2015).

Floating dosage forms may be classified into effervescent and non-effervescent systems (Bardonnet et al., 2006; Barrocas et al., 2007). The effervescent floating devices are constituted by a matrix of expandable polymers, polysaccharides or hydrophobic polymers associated with gas generating compounds such as sodium bicarbonate. When these systems reach the stomach, carbon dioxide is released, due to the acidity of gastric contents, and then trapped within the device, causing them to float. Non-effervescent systems are constituted by hydrocolloids which swell in the acid fluid causing the reduction in specific density, thus allowing the movement towards the top of the liquid, resulting in the fluctuation without the gas generator compound device (Barrocas et al., 2007; Ferrari et al., 2014).

The aim of this study was to develop effervescent floating microparticles using polymers with different properties, such as chitosan (CS; swellable polysaccharide), hydroxypropyl methylcellulose (HPMC; expandable polymer) and ethylcellulose (EC; water-insoluble polymer) for gastric retention of MT for $\mathrm{H}$. pylori treatment; and to evaluate their physicochemical characteristics, the in vitro drug release and floating properties in the simulated gastric medium.

\section{MATERIAL AND METHODS}

\section{Material}

Chitosan (low molecular weight; $75-85 \%$ deacetylated) was purchase from Sigma Aldrich (São Paulo, Brazil). Metronidazole was purchase from Audaz (São Paulo, Brazil). Ethylcellulose (Ethocel ${ }^{\mathrm{TM}}$ ) and hydroxypropyl methylcellulose (Methoce $\left.{ }^{\mathrm{TM}} \mathrm{K} 4 \mathrm{M}\right)$ were a gift from Colorcon (São Paulo, Brazil). Sodium bicarbonate was purchase from Synth (São Paulo, Brazil). All other reagents and solvents were of analytical grade.

\section{Preparation of floating microparticles}

Floating systems were prepared using two different methods according to the polymers solubility. Aqueous dispersion formulations were prepared to obtain floating microparticles with HPMC, a hydrophilic polymer. Emulsion formulations were prepared to obtain floating microparticles with EC, a water-insoluble polymer. CS was used in both types of formulations.

To both methods, the drug (MT) and CS were dissolved in acetic acid solution $(0.1 \mathrm{~N})$ and the sodium bicarbonate (gas generator) was dissolved in purified water. The composition of samples was described in Table I. Aiming to evaluate the floating ability and control of the MT release, the proportions between

TABLE I - Floating systems composition

Composition (g)

\begin{tabular}{lccccc}
\cline { 2 - 5 } Formulation & MT & $\begin{array}{c}\text { Sodium } \\
\text { bicarbonate }\end{array}$ & HPMC & EC & CS \\
\hline Control HPMC:CS & - & 0.50 & 1.25 & - & 1.25 \\
Control EC:CS & - & 0.50 & - & 1.25 & 1.25 \\
HPMC:CS 1:1 & 1.00 & 0.50 & 1.25 & - & 1.25 \\
HPMC:CS 1:3 & 1.00 & 0.50 & 0.85 & - & 1.65 \\
HPMC:CS 3:1 & 1.00 & 0.50 & 1.65 & - & 0.85 \\
EC:CS 1:1 & 1.00 & 0.50 & - & 1.25 & 1.25 \\
EC:CS 1:3 & 1.00 & 0.50 & - & 0.85 & 1.65 \\
EC:CS 3:1 & 1.00 & 0.50 & - & 1.65 & 0.85 \\
\hline MT:
\end{tabular}

MT: metronidazole; HPMC: hydroxypropyl methylcellulose; EC: Ethylcellulose; CS: chitosan. 
HPMC and CS, and between EC and CS, were varied in $1: 1,1: 3$ and $3: 1$.

Aqueous dispersion formulations were obtained varying the proportion of HPMC and CS, keeping the drug and the sodium bicarbonate content equal in all the samples. Formulations were prepared by mixing all components under magnetic stirring during 30 minutes. To prepare the emulsion formulations, two phases were prepared, an aqueous phase composed by CS, MT (both previously dissolved in acid solution), polyvinyl alcohol (PVA) at $1.0 \%(\mathrm{w} / \mathrm{v})$ and sodium bicarbonate, and an organic phase composed by EC dispersed in acetone. The two phases were also mixed under magnetic stirring during 30 minutes. The proportions of EC and CS varied. The solid content of all samples was $1.0 \%(4.0 \mathrm{~g})$, and the total volume prepared was $400 \mathrm{~mL}$, except control formulations (without drug) which were prepared with $3.0 \mathrm{~g}$ of solid content in $300 \mathrm{~mL}$.

Aqueous dispersion formulations and emulsion formulations were taken to spray dryer (mini, mod MSD 1.0, LABMAQ), under magnetic stirring to obtain the microparticles. The conditions of the process were inlet temperature of $100{ }^{\circ} \mathrm{C}$ for aqueous dispersion and $80{ }^{\circ} \mathrm{C}$ for emulsion formulations and the sample flow was 0.25 L. $h^{-1}$ for both systems.

\section{Physicochemical characterization of floating microparticles}

\section{Particle Size Analysis}

The average microparticles diameter was measured by dynamic light scattering method using ZetaSizer ${ }^{\circledR}$ equipment (Zetasizer Nanoseries, Malvern Instruments, United Kingdom). Microparticles were dispersed into water at a dilution of 1:500 and the homogeneous suspension could determine the average diameter of the microparticles and the size distribution (Hao et al., 2014).

\section{Scanning electron microscopy (SEM)}

SEM was performed using the SSX-550 Superscan (Shimadzu). Samples were brought to the vacuum oven TE 395 (Tecnal) and fixed in a metallic form and coating with gold in the IC-50 equipment Ion Coater (Shimadzu). The micrographs were obtained using accelerating voltages of $15 \mathrm{kV}$ in several magnifications.

\section{Fourier Transform Infrared Spectrometry (FTIR)}

The FTIR spectra were performed using an IR Prestige-21 (Shimadzu). In order to collect the spectra, a small amount of microparticles or pure constituents was mixed with $\mathrm{KBr}$ (Merck IR spectroscopy grade) and compressed to obtain tablets. The FTIR spectra, in absorbance mode, were obtained in the spectral region of $400-4000 \mathrm{~cm}^{-1}$ using a resolution of $2 \mathrm{~cm}^{-1}$.

\section{$X$-Ray Diffraction (XRD)}

The analyses were performed on an X-ray diffractometer (Shimadzu XRD-6000). Monochromatized $\mathrm{CuK}_{\alpha}$ radiation $(\lambda=0.154 \mathrm{~nm})$ was used as the $\mathrm{X}$-ray source operating at $40 \mathrm{kV}$. The current flow in the tube was at 40 $\mathrm{mA}$ and the spectrum was recorded in the range of $3^{\circ}$ to $60^{\circ} 2 \theta$ at a scan rate of $2^{\circ} 2 \theta \cdot \mathrm{min}^{-1}$ to check the crystal pattern of the pure drug and microparticles, as well as the other constituents of the formulations.

\section{Drug loading}

It was performed by pulverization to break microparticles and $100 \mathrm{mg}$ of powder were weighted, corresponding to $25 \mathrm{mg}$ of MT, and added in $50 \mathrm{~mL}$ flask with $\mathrm{HCl} 0.1$ mol. $\mathrm{L}^{-1}$. The mixture was stirred for 60 minutes on a magnetic stirrer. The obtained samples were filtered through cellulose acetate membrane $(0.45$ $\mu \mathrm{m})$ and analyzed by UV-Vis spectrophotometer at 277 $\mathrm{nm}$ (Oh, Heng, Chan, 2015). The assay was realized in sextuplicate. The related concentrations were calculated using calibration profiles based on absorbance versus concentration curves previously designed and standardized (range concentration of 0.625 to $25.0 \mu \mathrm{g} \cdot \mathrm{mL}^{-1} ; \mathrm{y}=0.0369 \mathrm{x}$ $\left.+0.0066 ; r^{2}=0.9998\right)$.

\section{In vitro characterization of the floating microparticles}

Floating ability

The floating ability of microparticles was evaluated according an adapted method described by Ferrari et al. (2014). $50 \mathrm{mg}$ of microparticles were added in $200 \mathrm{~mL}$ of simulated gastric fluid ( $\left.\mathrm{HCl} 0.1 \mathrm{~mol}^{-1}, \mathrm{pH} 1.2\right)$ at approximately $40^{\circ} \mathrm{C}$ at a bath of water with periodical stirring at $50 \mathrm{rpm}$. The lag time and the total floating time were visually analyzed.

\section{Drug release}

The dissolution studies were performed using a Dissolution Station (Nova Ética ${ }^{\circledR}$ model 299-6A TTS) based on United States Pharmacopoeia (2007) Apparatus II (paddle method). The acceptor fluid was maintained at $37 \pm 0.5^{\circ} \mathrm{C}$ with the rotation speed set at $50 \mathrm{rpm}$. The release medium was $400 \mathrm{~mL}$ of simulated gastric fluid $(\mathrm{pH}$ 1.2) for 4 hours. Test was performed in triplicate.

At appropriate time intervals $(15,30,45,60,90$, $120,150,180$ and $240 \mathrm{~min}), 10 \mathrm{~mL}$ of the samples were 
withdrawn and filtered through cellulose acetate membrane $(0.45 \mu \mathrm{m})$. The dissolution medium was replaced with the same volume maintaining the sink conditions. The filtrate was analyzed by UV spectrophotometer at 277 $\mathrm{nm}$. The concentrations were calculated using calibration profiles based on absorbance versus concentration curves previously designed and standardized (range concentration of 0.625 to $\left.25.0 \mu \mathrm{g} \cdot \mathrm{mL}^{-1} ; \mathrm{y}=0.0369 \mathrm{x}+0.0066 ; \mathrm{r}^{2}=0.9998\right)$. The corresponding drug release profiles were represented by plots of the cumulative temporal percent amount of drug released (calculated from the total amount of MT contained in each sample).

\section{Difference $\left(f_{1}\right)$ and Similarity $\left(f_{2}\right)$ Factors}

Difference factor $\left(f_{1}\right)$ is a measurement of the relative error between the two dissolution curves and Similarity factor $\left(f_{2}\right)$ measure the closeness between the two dissolution profiles. The factors were calculated according to the equations given below:

$$
\begin{gathered}
f_{1}=\frac{\sum_{t=1}^{n}\left|R_{t}-T_{t}\right|}{\sum_{t=1}^{n} R_{t}} \cdot 100 \\
f_{2}=50 \times \log \left\{\left[1+\frac{1}{n} \sum_{t=1}^{n}\left(R_{j}-T_{j}\right)^{2}\right]^{-0.5} \times 100\right\}
\end{gathered}
$$

where, $n$ is the number of time points, $\mathrm{R}_{\mathrm{j}}$ and $\mathrm{T}_{\mathrm{j}}$ are the dissolution values of the reference product and the test product, respectively, at each time point $j$. In order to consider the dissolution profiles similar, $f_{l}$ values should be between 0 and 15 , and $f_{2}$ values higher than $50(50-100)$, showing the similarity of the dissolution profiles (Costa, Lobo, 2001).

\section{Statistical analysis}

The statistical analyses were realized by Student's t-test (independent samples) with $p<0.05$ as the minimal level of significance (Martinac et al., 2005). Data were analyzed in Microsoft Office Excel 2007.

\section{RESULTS AND DISCUSSION}

Microparticles were obtained by spray drying process. All samples presented a slightly yellow color. The yield of formulations was similar between samples prepared by the same method (or same polymer). Samples prepared with HPMC showed $64.71( \pm 10.85) \%$ of yield, while samples with EC showed $47.28( \pm 4.98) \%$. These low percentages of yield are due to the equipment, which has a larger drying chamber and a cyclone chamber in which microparticles remain adhered. The method used to prepare the formulations also was responsible for the reduction of the percentage of yield, showing lower results in emulsion formulations.

\section{Physicochemical characterization of floating microparticles}

The results of the mean diameter of the microparticles (Table II) show that all samples presented average particles size ranging from 1.05 to $2.20 \mu \mathrm{m}$. Formulations prepared with HPMC and CS presented similar size $(p>0.05)$. The particle size of EC and CS formulations was statistically different comparing formulations $1: 1$ and $1: 3(p=0.006)$, indicating that the larger amount of CS contributed to the larger size of microparticles.

Polydispersity index is an index ranging from zero, when all microparticles of the dispersion presenting

TABLE II - Results of microparticles characterization

\begin{tabular}{lcccc}
\hline Formulation & $\begin{array}{c}\text { Average particle size } \\
(\boldsymbol{\mu m})\end{array}$ & $\begin{array}{c}\text { Polidispersity } \\
\text { index }\end{array}$ & $\begin{array}{c}\text { Zeta Potential } \\
(\mathbf{m V})\end{array}$ & $\begin{array}{c}\text { Entrapment efficiency } \\
(\boldsymbol{\%})\end{array}$ \\
\hline Control HPMC:CS & $1.43( \pm 0.76)$ & $1.000( \pm 0.000)$ & $12.45( \pm 2.40)$ & - \\
Control EC:CS & $2.04( \pm 0.81)$ & $1.000( \pm 0.000)$ & $7.21( \pm 3.02)$ & - \\
HPMC:CS 1:1 & $1.49( \pm 0.54)$ & $1.000( \pm 0.000)$ & $-2.68( \pm 2.87)$ & $31.69( \pm 0.73)$ \\
HPMC:CS 1:3 & $1.48( \pm 0.70)$ & $1.000( \pm 0.000)$ & $-6.25( \pm 2.94)$ & $42.67( \pm 1.84)$ \\
HPMC:CS 3:1 & $1.05( \pm 0.31)$ & $0.873( \pm 0.219)$ & $-4.00( \pm 2.42)$ & $26.58( \pm 0.72)$ \\
EC:CS 1:1 & $1.09( \pm 0.49)$ & $1.000( \pm 0.000)$ & $-3.71( \pm 1.96)$ & $44.64( \pm 1.74)$ \\
EC:CS 1:3 & $2.20( \pm 0.32)$ & $0.663( \pm 0.298)$ & $-7.66( \pm 2.41)$ & $36.91( \pm 2.21)$ \\
EC:CS 3:1 & $2.06( \pm 0.63)$ & $0.883( \pm 0.101)$ & $-5.85( \pm 3.53)$ & $66.91( \pm 2.01)$ \\
\hline
\end{tabular}

MT: metronidazole; HPMC: hydroxypropyl methylcellulose; EC: Ethylcellulose; CS: chitosan. 
relatively the same size, and 1.0 , when the average particle diameter is heterogeneous (Oliveira et al., 2013). Microparticles composed by HPMC and CS presented index of 1.0 or near of it, indicating low homogeneity of the particle size. EC and CS samples presented index ranging from 0.663 to 1.0 . The particle size could be related to the method of preparation, in which samples obtained by emulsion were more homogeneous than microparticles prepared by aqueous dispersion.

Zeta potential is a measure that indicates the electrical potential that arises when microparticles acquire electric charge on its surface in contact with a liquid. This electric potential is influenced by changes in the particle interface with the dispersing medium, due to the dissociation of functional surface groups or the adsorption of ionic species present in the aqueous dispersion (Schaffazick, Guterres, 2003). The cellulose derivatives polymers, HPMC and EC, are non ionic materials and the CS is a positive polysaccharide due to the amino groups, which acquire electrical charge. The drug, MT, contains a nitro group $\left(\mathrm{NO}_{2}\right.$; Figure 1) presenting negative charge in aqueous solution. Results of microparticles showed negative charge, which may be related to the presence of the drug in the microparticles surface, indicating that the drug was not entirely encapsulated. This partial encapsulation could be due to a high quantity of drug added in formulations, in which the proportion of drug and polymers was $1: 2.5$. These proportions aimed to encapsulate a high amount of drug; however, the potential zeta analysis, as the entrapment efficiency study showed that the drug was not totally encapsulated by polymers (Table II).

The SEM photomicrographs of microparticles, with magnification of $2500 \mathrm{x}$, show the morphology and the surface of samples (Figure 2).

The photomicrographs of the HPMC and CS microparticles' outer surface (Figure 2 A-C) showed that the size of particles was not uniform, a typical characteristic of particles produced by spray drying. Photomicrographs obtained by EC and CS samples (Figure 2 D-F) presented more uniform particles, as compared to HPMC and CS microparticles, but also showed imperfections on their
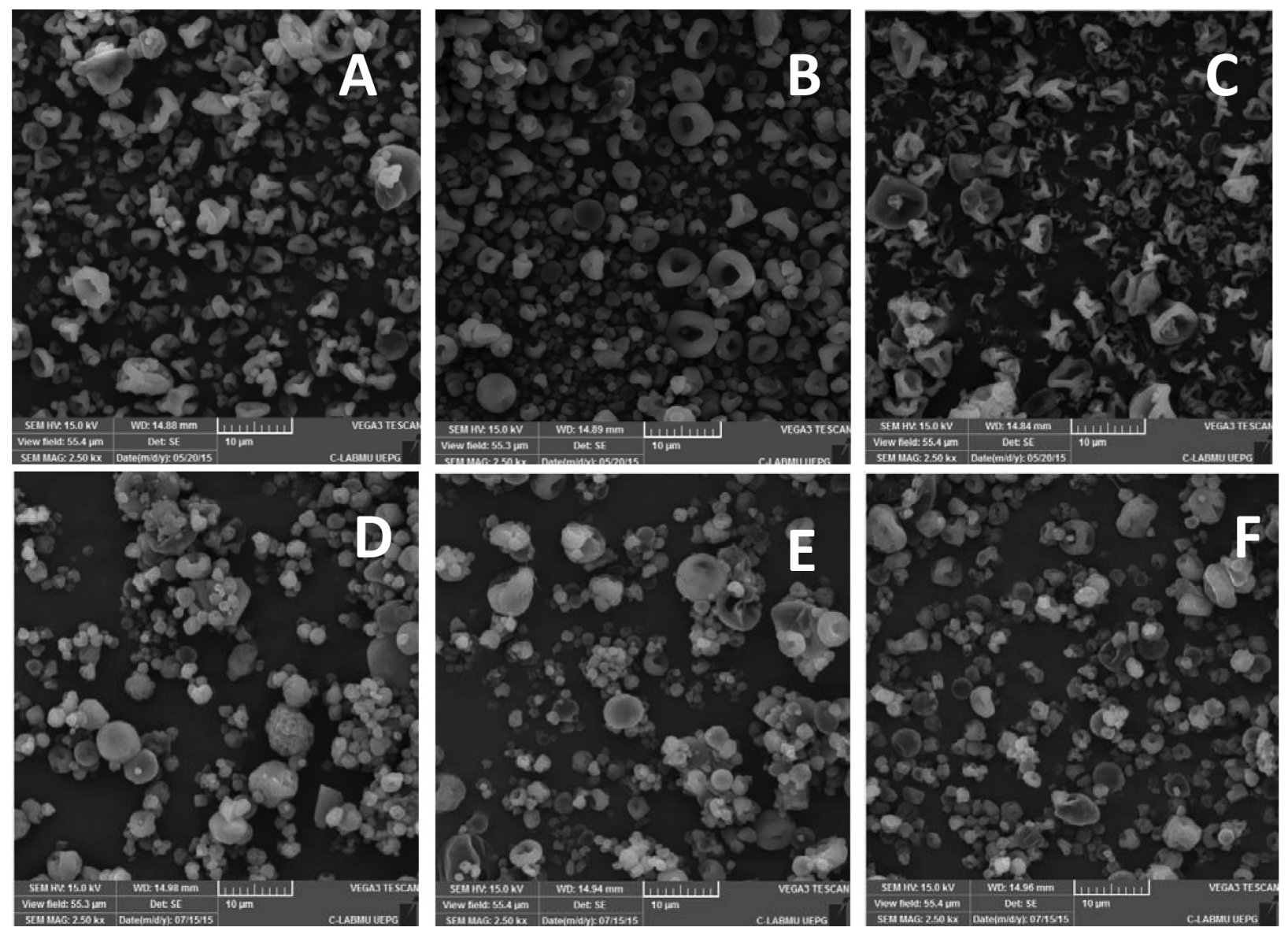

FIGURE 2 - Photomicrographs of microparticles: (A) HPMC:CS 1:1; (B) HPMC:CS 1:3; (C) HPMC:CS 3:1; (D) EC:CS 1:1; (E) EC:CS 1:3; (F) EC:CS 3:1 (magnification of 2,500 x). MT: metronidazole; HPMC: hydroxypropyl methylcellulose; EC: ethylcellulose; CS: chitosan. 
surfaces, as well as different sizes. These characteristics can be due to the conditions of emulsification process, such as rate of stirring, used solvents and type of emulsifier (Rinaldi et al., 2009).

According to Stulzer et al., (2007), the morphology of microparticles is probably due to the obtainment process, which often produces amorphous compounds, due to the rapid drying process, preventing a uniform organization of particles. The main variables of the drying process are operational, such as inlet and outlet air temperature, air flow pattern, temperature distribution and humidity and durability time, in addition to structural variables, e.g. the atomizer type. All these variables can influence in the shaping of microparticles and also influence the encapsulation efficiency, as occurred in all formulations (Table II).

There are many reasons that cause the low entrapment efficiency: (i) duration of spray drying process; (ii) low viscosity of the sample, which facilitates the internal circulation of droplets, causing coalescence and resulting in larger droplets. Furthermore, the increase of internal circulation hinders the formation of the membrane during the drying process, decreasing the drug retention into microparticles, i.e., lower encapsulation efficiency; (iii) emulsion stability, which is related to the encapsulation efficiency, since a larger amount of unencapsulated drug can adhere to the particle' surface (Barbosa, Borsarelli, Mercadante, 2005; Soottitantawat et al., 2003, 2005). Besides, other operation variables and characteristics of the device itself can contribute to the results found.

Microparticles composed by HPMC and CS showed entrapment efficiency varying from 26.6 to $42.7 \%$, and the sample containing a higher amount of CS yielded a better drug encapsulation. CS is a hydrophilic polymer, soluble only in acid solutions and HPMC is also hydrophilic, swellable, soluble in water and $\mathrm{pH}$-independent. The sample composed by HPMC and CS containing a higher amount of CS presented the highest value of encapsulation efficiency, indicating more ability of CS to encapsulate the MT.

On the other hand, samples prepared with EC and CS containing a higher proportion of CS presented the lowest encapsulation efficiency (36.9\%). EC is a hydrophobic polymer, and it's high amount in the formulation promoted more drug retaining $(66.9 \%)$, while samples composed by high amounts of CS, in this case, presented low encapsulation of the MT.

\section{FTIR and XRD studies}

FTIR technique allows the identification of organic compounds through the functional groups present in the molecules. Figure 3 shows the spectra of the formulations and their respective constituents.

The absorption bands at $3223 \mathrm{~cm}^{-1}$ (O-H stretching), $3100 \mathrm{~cm}^{-1}$ (C-H and $\mathrm{C}=\mathrm{CH}$ stretching), $1535 \mathrm{~cm}^{-1}(\mathrm{~N}-\mathrm{O}$ stretching), $1370 \mathrm{~cm}^{-1}\left(\mathrm{NO}_{2}\right.$ symmetric stretching) and $1076 \mathrm{~cm}^{-1}$ (C-O stretching, $\mathrm{C}-\mathrm{H}$ in plane bending) were assigned as the fingerprints of MT (Wearley, Anthony, 1976; Ramukutty, Ramachandran, 2012), and the MT spectrum shows their characteristics bands: $3200-3600$ $\mathrm{cm}^{-1}$ attributed to the $\mathrm{O}-\mathrm{H}$ stretching, $3221-3101 \mathrm{~cm}^{-1}$ (N-H stretching), 2982-2937 $\mathrm{cm}^{-1}$ (C-H stretching), 1300$1600 \mathrm{~cm}^{-1}$ attributed to the $\mathrm{NO}_{2} ; 1354-1180 \mathrm{~cm}^{-1}(\mathrm{C}-\mathrm{O}$ stretching), $1428-1368 \mathrm{~cm}^{-1}$ (C-H bending, in plane), $1340 \mathrm{~cm}^{-1}$ (C-C stretching), $864 \mathrm{~cm}^{-1}$ (C-H out of plane bending), $825 \mathrm{~cm}^{-1}$ (C-H out of plane bending and $\mathrm{C}-\mathrm{N}$ stretching), $744 \mathrm{~cm}^{-1}\left(\left(\mathrm{CH}_{2}\right)_{2}\right.$ rocking $)$.

Spectrums were separated in the range of 1600-600 to better viewing of the peaks. Bands of the MT were not presented in the spectrum of control microparticles (without drug), signalized by dotted lines. Figure 3B shows the peak of MT in $1265.35 \mathrm{~cm}^{-1}$, present in the microparticles, except for the control sample, as well as the peaks in $864.14,826.53$ and $744.55 \mathrm{~cm}^{-1}$, which did not appear in the control sample, confirming the drug encapsulation into microparticles. Figure 3D shows the MT peaks at 1533.47, 1189.16, 825.56 and $744.55 \mathrm{~cm}^{-1}$, only present in the microparticles containing the drug.

There is a predominance of polymers characteristic bands (Table III) in all microparticles samples, and the main bands of polymers and the drug were presented in microparticles (with less intensity), indicating no chemical linkage among them.

$\mathrm{XRD}$ is an important technique to study the crystal structure typically found in compounds. Figure 4 shows the XRD patterns for the different formulations of microparticles.

MT sample shows high crystalline structure, due to the presence of several sharp peaks at 12.02, 13.55, $17.89,21.27,24.54,27.30,29.07$ and $33.57^{\circ} 20$. Polymers showed two peaks: CS at 10.18 and $19.72^{\circ} 2 \theta$, HPMC at 9.58 and $19.36^{\circ} 2 \theta$ and $\mathrm{EC}$ at 7.96 and $20.04^{\circ} 2 \theta$. These polymers present crystalline and amorphous phase when pure and in solid state (Suksaeree et al., 2015).

Microparticles showed low peak intensity and baseline shift of the diffractogram was observed, due to the presence of polymers when compared to the drug pattern, similar to Parida et al. (2016) results. The broad and distorted hump in a wide range in the microparticles was due to the amorphous phase and the decrease in crystallinity of the drug that followed encapsulation in the polymeric microparticles (Singh et al., 2015). However, 

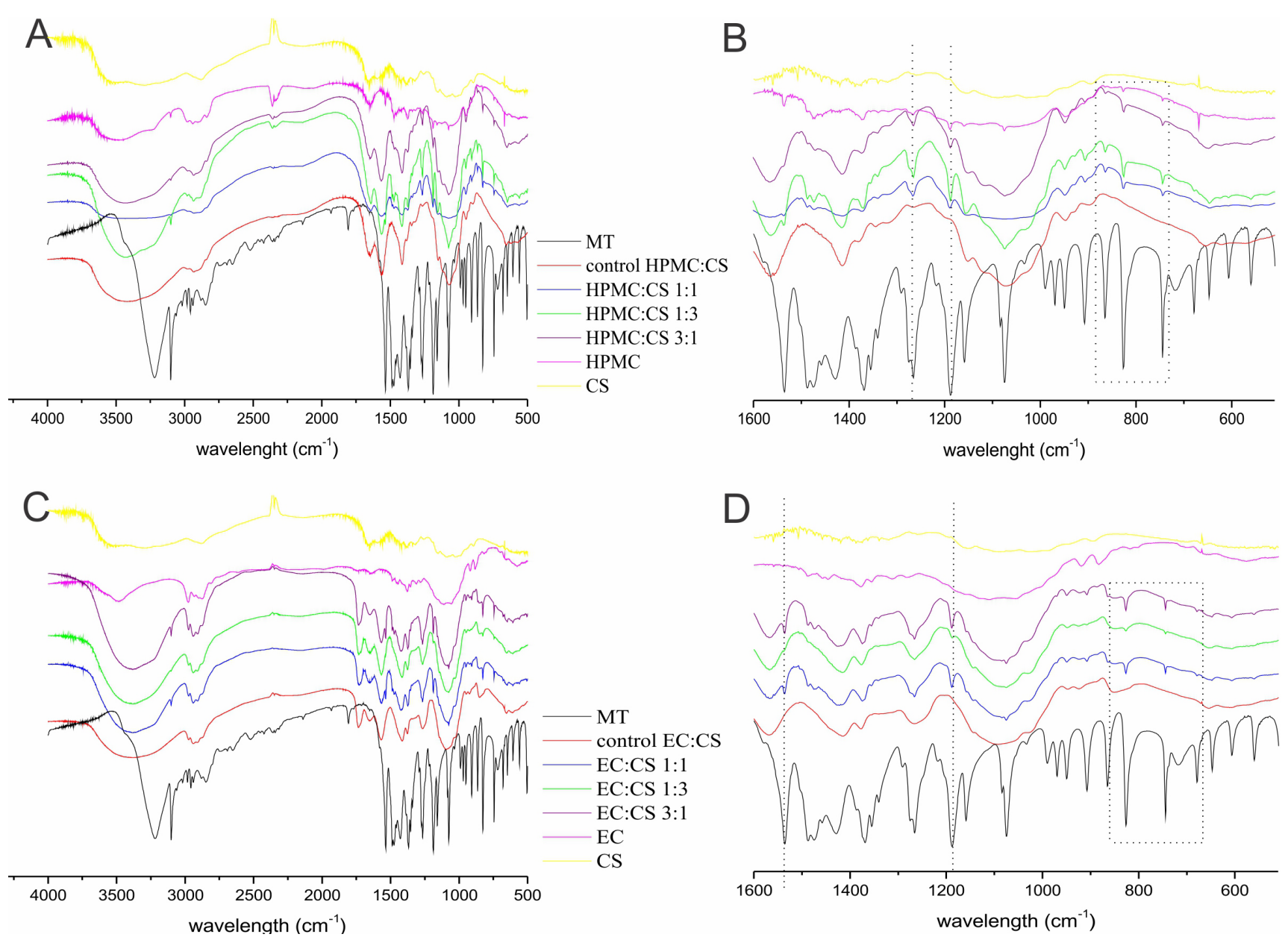

FIGURE 3 - FTIR spectrums of formulations and pure constituents: (A) HPMC and CS samples: wavelength range: $4000 \mathrm{~cm}^{-1}$ to $500 \mathrm{~cm}^{-1}$; (B) HPMC and CS samples: wavelength range: $1600 \mathrm{~cm}^{-1}$ to $600 \mathrm{~cm}^{-1}$; (C) EC and CS samples: wavelength range: $4000 \mathrm{~cm}^{-1}$ to $500 \mathrm{~cm}^{-1}$; (D) EC and CS samples: wavelength range: $1600 \mathrm{~cm}^{-1}$ to $600 \mathrm{~cm}^{-1}$. MT: metronidazole; HPMC: hydroxypropyl methylcellulose; EC: ethylcellulose; CS: chitosan.

TABLE III - Characteristics bands of used polymers composing the floating microparticles

\begin{tabular}{|c|c|c|c|}
\hline Bands $\left(\mathrm{cm}^{-1}\right)$ & CS & HPMC & EC \\
\hline $3400-2400$ & - & O-H stretching & O-H stretching \\
\hline $3180-3350$ & $\mathrm{NH}_{2}$ stretch & - & - \\
\hline 2900- 2870 & - & methoxy group $\left(\mathrm{C}-\mathrm{CH}_{3}\right)$ & C-H stretching \\
\hline 1735 & - & $\mathrm{C}=\mathrm{O}$ stretching (ester group) & - \\
\hline $1650-1665$ & $\begin{array}{c}\mathrm{C}=\mathrm{O} \text { stretching (amine of the } \\
\text { acetamido) }\end{array}$ & aromatic ring & - \\
\hline $1560-1610$ & $\begin{array}{l}\text { axial deformation } \\
\left(\mathrm{NH}_{2} \text { group }\right)\end{array}$ & - & - \\
\hline $1444-1375$ & - & - & $\mathrm{CH}_{3} ; \mathrm{CH}_{2}$ \\
\hline $1300-1000$ & C-O stretching & - & C-O-C stretching (cyclic ether) \\
\hline 1276 & - & ester group & - \\
\hline $1200-1000$ & - & ether group & - \\
\hline 744 & - & monosubstituted aromatic ring & - \\
\hline
\end{tabular}

CS: chitosan; HPMC: hydroxypropyl methylcellulose; EC: ethylcellulose. 



FIGURE 4 - XRD of microparticles and their constituents: (A) HPMC and CS samples; (B) EC and CS samples. MT: metronidazole; CS: chitosan; HPMC: hydroxypropyl methylcellulose; EC: rthylcellulose.

some peaks of MT (with lower intensity) were observed in microparticles. HPMC and CS microparticles showed peaks at $9.10,12.10,13.74,19.90,25.30,27.43,33.19^{\circ}$ $2 \theta$, and EC and CS microparticles at 7.90, 12.16, 13.66, $19.43,27.70,33.24^{\circ} 2 \theta$, related to the drug and polymers, showing that microparticles presented semi-amorphous structure, which indicates partial drug encapsulation.

\section{In vitro characterization of the floating microparticles}

The microparticles floating ability is shown in Figure 5. All samples floated immediately when added in contact with the simulated gastric fluid. Ten minutes after, $10 \%$ of microparticles sinked, except the EC:CS $3: 1$ formulation (green solid line) which only $50 \%$ of microparticles remained dispersed. After 30 min of assay, samples of HPMC:CS microparticles were hydrated and remained floating during 2 hours.

HPMC and CS microparticles (dotted lines) showed the same profile, regardless the proportions between CS and HPMC, indicating that the quantity of polymers did not influence the flotation time. In contact with simulated gastric fluid, the microparticles immediately floated due to their low density and maintained due to the medium absorption by polymers, which swelled, combined with the gas generator substance (sodium bicarbonate) allowing the flotation for 2 hours.



FIGURE 5 - Floating ability of microparticles. CS: chitosan; HPMC: hydroxypropyl methylcellulose; EC: rthylcellulose.

EC and CS microparticles (solid line) showed different floating profiles, however all samples immediately floated in contact with the medium. EC:CS 1:1 and EC:CS 3:1 microparticles remained floating during a reduced time and after one hour and a half all microparticles stopped floating. These formulations contain high proportions of EC (equal or more than CS), which is insoluble and not swells. Therefore, the swelling of microparticles was limited and was not sufficient to maintain their flotation. EC:CS 1:3 sample, containing a high quantity of CS, floated during 2 hours; due to the gel layer formation 
(by CS), which swelled and sustained the gas generated by sodium bicarbonate allowing the flotation of the microparticles.

The study of drug release from floating microparticles was presented in Figure 6. MT is a water soluble drug, belonging to the class I of Biopharmaceutical Classification System, i.e. the MT release occurs fast and its dissolution is not a limiting step for the absorption. The prepared microparticles exhibited prolonged drug release in the simulated gastric fluid.

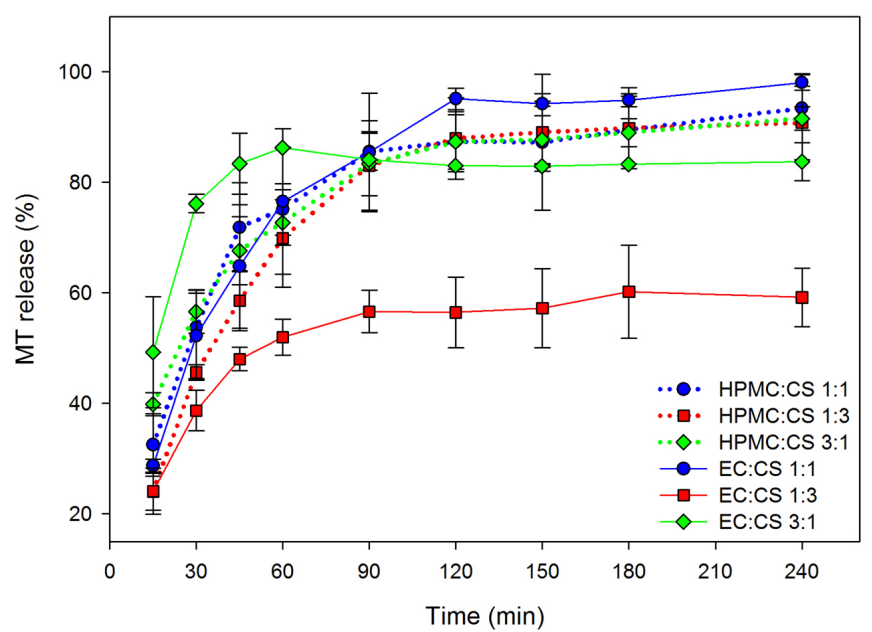

FIGURE 6 - Drug release profile of floating microparticles in simulated gastric fluid. MT: metronidazole; CS: chitosan; HPMC: hydroxypropyl methylcellulose; EC: ethylcellulose.

In the first hour, $75 \%$ of the drug were released from HPMC and CS microparticles, and 95\% of MT were released in 4 hours. Statistical analysis shows that the drug released from HPMC:CS 1:1 and HPMC:CS $1: 3\left(\mathrm{p}=0.0122 ; f_{1}=11.82 ; f_{2}=98.07\right)$ formulations were different. HPMC:CS 1:3 microparticles contains more CS and it was responsible for the different drug release profile. It was found that CS decreases the rate of drug release from microparticles in the beginning of the dissolution test in simulated gastric fluid. The obtained results in the study conducted by Ritger, Peppas (1987), showed that the CS hydration and gel formation takes place more readily at acid $\mathrm{pH}$ levels $(\mathrm{pH} 1.2)$ than at $\mathrm{pH}$ levels close to neutral, due to its cationic nature (Sahu, Verma, Singh, 2012). Higher amounts of CS resulted in better control of drug release in the first hour of the test. HPMC also contributed in prolonging the drug release due to its swelling, associated with the CS swelling. However, in formulations containing equal or a higher quantity of HPMC (than CS) the drug release were similar ( $\mathrm{p}=$ $0.5950 ; f_{1}=5.96 ; f_{2}=70.06$ ).

EC:CS 1:3 sample presented drug release statistically different from all other samples ( $\mathrm{p}<0.05 ; f_{1}>15 ; f_{2}<50$ ), showing $60 \%$ of drug released in 4 hours. This sample also contains a higher quantity of CS. EC is an insoluble polymer that does not swell and reduce the CS swelling (CS absorbs the gastric fluid fast, even though it is limited). Probably the association of CS and EC induced a stable and rigid gel layer, able to control the water uptake into the microparticles and this gel layer controlled the MT release from microparticles. EC, being hydrophobic, has recently been reported to be an excellent backing material, given its low water permeability and moderate flexibility, due to this insolubility preventing the penetration of water into microparticles (Remunan-Lopez et al., 1998; Nunthanid et al., 2009).

Formulations containing EC and CS 3:1 were also statistically different of all other samples $\left(f_{1}>15 ; f_{2}<50\right)$, showing fast initial drug delivery followed by a plateau. This sample contains a lower quantity of CS and the MT was quickly released. It may be attributed to the CS low amount, because EC has a low water permeability while both $\mathrm{CS}$ and the drug are relatively soluble at low $\mathrm{pH}$, therefore this formulation had lower gel formation in acidic $\mathrm{pH}$, allowing the fast drug release by diffusion (Adebisi, Conway, 2014).

MT release from HPMC:CS 1:1 and from EC:CS 1:1 samples showed similar profile until 90 min of dissolution test $\left(\mathrm{t}_{85 \%} ; f_{1}=4.32 ; f_{2}=64.93\right)$; however it was significantly different $(\mathrm{p}=0.0438)$ after the first second hour, and a greater quantity of drug was released from HPMC and CS microparticles than from EC and CS microparticles. Samples presented the same proportion between polymers, but in the formulation prepared with EC, the CS swelling was reduced and the medium intake occurred slowly, prolonging the MT delivery.

The development of floating gastroretentive systems requires the in vitro assessment of drug release profiles as well as the assessment of the floating behavior. Thus, a combined evaluation of formulations, which has no floating lag time and maintains its floating capabilities while releasing the drug was performed (Figure 7). After completing the drug release, the delivery systems should lose their floating capability, allowing the gastric emptying of the microparticles and thus preventing possible accumulation of microparticles in the stomach after multiple administering.

According to Amit et al. (2011), the risk of microparticles accumulation in the stomach is negligible following a single administration; however, potential risk of the aggregation and accumulation of drug-depleted microparticles in the stomach increases after multiple and sequential administrations. Therefore, the microparticles' 


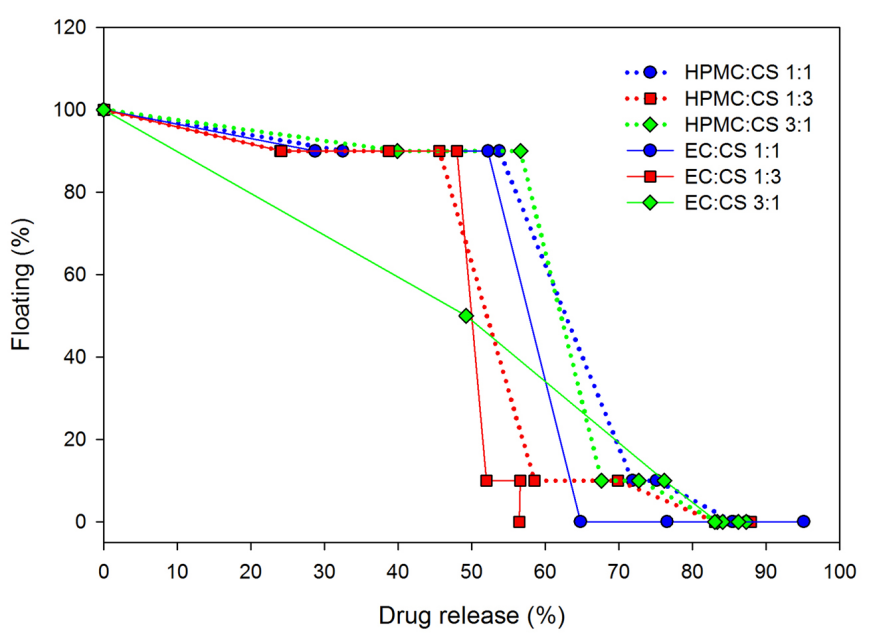

FIGURE 7 - Relation between floating ability and drug release of microparticles. CS: chitosan; HPMC: hydroxypropyl methylcellulose; EC: rthylcellulose.

ability to remain floating during the drug release and to sink after drug depletion is the ideal characteristic for floating microparticles.

Results showed that all microparticles remained floating while around $60 \%$ of the drug were releasing, except EC:CS 3:1 formulation, in which $50 \%$ of microparticles floated during the release of $40 \%$ of the MT. These results reveal that microparticles remain floating while most of the drug is being released.

The developed microparticles exhibited different flotation and drug release profiles, according to the polymer composition. EC:CS 1:3 microparticles remained floating during $100 \mathrm{~min}$, and after 4 hours, only $60 \%$ of drug were released while no microparticles remained floating.

HPMC:CS 1:1 and HPMC:CS 3:1 formulations showed suitable relation between floating ability and MT release, i.e. $90 \%$ of microparticles remained floating during $60 \%$ of MT release, and only after $80 \%$ of drug release the microparticles stopped to float. The amount of HPMC did not influence the relationship between floating and drug release, while the amount of CS caused influence (red dotted line; Figure 7), because $10 \%$ of microparticles remained floating after around $60 \%$ of the drug were released from sample containing a greater quantity of CS than HMPC.

Microparticles of HPMC:CS formulations can be classified as Type I in the model floating behavior category, according to Eberle et al. (2016), who refers to the floating characteristics of hydrophilic eroding systems, in which the floating decrease due to predominant dissolution of the microparticles components. Despite $80 \%$ of the drug were released in 2 hours, the maintenance of the flotation is essential to promote the microparticles retention in the stomach and after the drug release the microparticles should stop floating to avoid accumulation.

\section{CONCLUSIONS}

Floating microparticles were successfully obtained and characterized to potential gastroretentive effect, and possible use for gastric disease treatment, such as $H$. pylori infections. Floating microparticles composed by chitosan and one hydrophilic (HPMC) or one hydrophobic (EC) polymer were developed. Physicochemical characterization has shown the drug encapsulation and did not indicate chemical linkage occurrence between components. The microparticles floating ability study revealed no difference among the HPMC:CS samples, while microparticles containing a higher amount of EC presented poor flotation. The drug release study demonstrated better control of the MT release by EC:CS 1:3 sample, and similar profiles among HPMC:CS samples. However, the microparticles composed by HPMC and CS presented the best relationship between floating ability and controlled drug release and it is believed to be ideal for floating gastroretentive systems regarding safe administration.

\section{ACKNOWLEDGMENTS}

Authors acknowledge to Complex Multi-User Laboratories (C-LABMU) of UEPG, to Multi-User Laboratory of the Postgraduate Program in Pharmaceutical Sciences UEPG/UNICENTRO and to Medicinal Chemistry and Quality Laboratory of Department of Pharmaceutical Sciences of UEPG.

\section{REFERENCES}

ABOU YOUSSEF, N.A.; KASSEM, A.A.; EL-MASSIK, M.A.; BORAIE, N.A. Development of gastroretentive metronidazole floating raft system for targeting Helicobacter pylori. Int. J. Pharm., v.486, n.1, p.297-305, 2015.

ADEBISI, A.O.; CONWAY, B.R. Lectin-conjugated microspheres for eradication of Helicobacterpylori infection and interaction with mucus. Int. J. Pharm., v.470, n.1, p.2840, 2014.

AMIT, J.K.; RAMMULRAJSINH, R.; SONALI, D.; KINAL, P.; PRADEEP, A. Hydrodynamically Balanced Systems (HBS): innovative approach of gastroretention: a review. Int. J. Pharm. Tech. Res., v.3, n.3, p.1495-1508, 2011. 
ASGHAR, L.F.; CHANDRAN, S. Multiparticulate formulation approach to colon specific drug delivery: current perspectives. J. Pharm. Pharm. Sci., v.9, n.3, p.327-338, 2006.

BARBOSA, M.I.M.J.; BORSARELLI, C.D.; MERCADANTE, A.Z. Light stability of spray dried bixin encapsulated with different edible polysaccharide preparations. Food Res. Int., v.38, n.8/9, p.989-994, 2005.

BARDONNET, P.L.; FAIVRE, V.; PUGH, W.J.; PIFFARETTI, J.C.; FALSON, F. Gastroretentive dosage forms: overview and special case of Helicobacter pylori. J. Control. Rel., v.111, n.1/2, p.1-18, 2006.

BARROCAS, P.M.C.; SANTOS, D.F.G.; FERREIRA, D.C.; COELHO, P.M.B.S.; OLIVEIRA, R.C.S.; VEIGA, F.J.B. Sistemas farmacêuticos gastrorretensivos flutuantes. Rev. Bras. Cienc. Farm., v.43, n.3, p.325-334, 2007.

CHEN, R.-N.; HO, H.-O.; YU, C.-Y.; SHEU, M.-T. Development of swelling/floating gastroretentive drug delivery system based on a combination of hydroxyethyl cellulose and sodium carboxymethyl cellulose for Losartan and its clinical relevance in healthy volunteers with CYP2C9 polymorphism. Eur. J. Pharm. Sci., v.39, p.8289, 2010.

COSTA, P.; LOBO, J.M.S. Influence of dissolution medium agitation on release profiles of sustained-release tablets. Drug Dev. Ind. Pharm., v.27, p.811-817, 2001.

EMARA, L.H.; ABDOU, A.R.; EL-ASHMAWY, A.A.R.; MURSI, N.M. Preparation and evaluation of metronidazole sustained release floating tablets. Int. J. Pharm. Pharm. Sci., v.6, n.9, p.198-204, 2014.

EBERLE, V.A.; HARING, A.; SCHOELKOPF, J.; GANE, P.A.; HUWYLER, J.; PUCHKOV, M. In silico and in vitro methods to optimize the performance of experimental gastroretentive floating mini-tablets. Drug Dev. Ind. Pharm., v.42, p.808-817, 2016.

FERRARI, P.C.; GROSSKLAUSS, D.B.B.S.; ALVAREZ, M.; PAIXÃO, M.; ANDREIS, U.; CRISPIM, A.G.; CASTRO, A.; EVANGELISTA, R.C.; MIRANDA, J.C.A. A novel automated alternating current biosusceptometry method to characterization of controlled-release magnetic floating tablets of metronidazole. Drug Dev. Ind. Pharm., v.40, n.8, p.1123-1131, 2014.
GARCIA, A.; SALAS-JARA, M.J.; HERRERA, C.; GONZÁLEZ, C. Biofilm and Helicobacter pylori: from environment to human host. World J. Gastroenterol., v.20, n.19, p.5632-5638, 2014.

GUimarÃes, J.; CORVELO, T.C.; BARILE, K.A. Helicobacter pylori: fatores relacionados à sua patogênese. Rev. Paraense Med., v.22, n.1, p.33-38, 2008.

HAO, S.; WANG, Y.; WANG, B.; ZOU, Q.; ZENG, H.; CHEN, X.; LIU, X.; LIU, J.; YU, S. A novel gastroretentive porous microparticle for anti-Helicobacter pylori therapy: preparation, in vitro and in vivo evaluation. Int. J. Pharm, v.463, p.10-21, 2014.

KRISHNAIAH, Y.S.R.; VEER RAJU, P.; DINESH KUMARI, B.; JAYARAM, B.; RAMA, B.; RAJU V.; BHASKAR P. Pharmacokinetic evaluation of guar gum-based colontargeted oral drug delivery systems of metronidazole in healthy volunteers. Eur. J. Drug Metab. Pharmacokinet., v.28, n.4, p.287-294, 2003.

LEMIEUX, M.; GOSSELIN, P.; MATEESCU, M.A. Carboxymethyl starch mucoadhesive microspheres as gastroretentive dosage form. Int. J. Pharm., v.496, n.2, p.497-508, 2015.

MALFERTHEINER, P.; MEGRAUD, F.; O'MORAIN, C.A.; ATHERTON, J.; AXON, A.T.R.; BAZZOLI, F.; GENSINI, G.F.; GISBERT, J.P.; GRAHAM, D.Y.; ROKKAS, T.; EL-OMAR, E.M.; KUIPERS, E.J.; EUROPEAN HELICOBACTER STUDY GROUP(EHSG). Management of Helicobacter pylori infection-the Maastricht IV/Florence consensus report. Gut, v.61, p.646-664, 2012.

MARTINAC, A.; FILIPOVIC-GRCIC, J.; VOINOVICH, D.; PERISSUTTI, B.; FRANCESCHINIS, E. Development and bioadhesive properties of chitosan-ethylcellulose microspheres for nasal delivery. Int. J. Pharm., v.291, n.1, p.69-77, 2005.

NUNTHANID, J .; LUANGTANA - ANAN, M .; SRIAMORNSAK, P.; LIMMATVAPIRAT, S.; HUANBUTTA, K.; PUTTIPIPATKHACHORN, S. Use of spray-dried chitosan acetate and ethylcellulose as compression coats for colonic drug delivery: effect of swelling on triggering in vitro drug release. Eur. J. Pharm. Biopharm., v.71, n.2, p.356-361, 2009. 
OH, C.M.; HENG, P.W.S.; CHAN, L.W. Influence of hydroxypropyl methylcellulose on metronidazole crystallinity in spray-congealed polyethylene glycol microparticles and its impact with various additives on Metronidazole release. AAPS PharmSciTech, v.16, n.6, p.1357-1367, 2015.

OLIVEIRA, A.M.; JAGER, E.; JAGER, A.; STEPÁNEK, P.; GIACOMELLI, F.C. Physicochemical aspects behind the size of biodegradable polymeric nanoparticles: a step forward. Colloids Surf., A, v.436, p.1092-1102, 2013.

PARIDA, P.; MISHRA, S.C; SAHOO, S.; BEHERA, A.; NAYAK, B.P. Development and characterization of ethylcellulose based microsphere for sustained release of nifedipine. J. Pharm. Anal., v.6, p.341-344, 2016.

PAYÃO, S.L.M.; RASMUSSEN, L.T. Helicobacter pylori and its reservoirs: a correlation with the gastric infection. World J. Gastrointest. Pharmacol. Ther., v.7, n.1, p.126-132, 2016.

PRAJAPATI, S.T.; PATEL, L.D.; PATEL, D.M. Gastric floating matrix tablets: design and optimization using combination of polymers. Acta Pharmaceut., v.58, p.221-229, 2008.

PRASANTHI, C.H.; PRASANTHI, N.L.; MANIKIRAN, S.S.; RAO, N.R. Focus on current trends in the treatment of Helicobacter pylori infection: an update. Int. J. Pharm. Sci. Rev. Res., v.9, n.1, p.42-51, 2011.

PRIYADARSHINI, R.; NANDI, G.; CHANGDER, A.; CHOWDHURY, S.; CHAKRABORTY, S.; GHOSH, L.K. Gastroretentive extended release of metformin from methacrylamide-g-gellan and tamarind seed gum composite matrix. Carbohydr. Polym., v.137, p.100-110, 2016.

RAJAB, M.; JOUMA, M.; NEUBERT, R.H.H.; DITTGEN, $\mathrm{M}$. Influence of water-soluble polymers on the in vitro performance of floating mucoadhesive tablets containing metformin. Drug Dev. Ind. Pharm., v.40, n.7, p.879-885, 2014.

RAMUKUTTY, S.; RAMACHANDRAN, E. Crystal growth by solvent evaporation and characterization of metronidazole. J. Crystal Growth, v.351, n.1, p.47-50, 2012.

RAPOLU, K.; SANKA, K.; VEMULA, P.K.; AATIPAMULA, V.; MOHD, A.B.; DIWAN, P.V. Optimization and characterization of gastroretentive floating drug delivery system using Box-Behnken design. Drug Dev. Ind. Pharm., v.38, p.1-8, 2012.
REMUNAN-LOPEZ, C.; PORTERO, A.; VILA-JATO, J.L.; ALONSO, M.J. Design and evaluation of chitosan/ ethylcellulose mucoadhesive bilayered devices for buccal drug delivery. J. Control. Rel., v.55, n.2, p.143-152, 1998.

RINALDI, A.P.T.; MAZERA, S.K.; PEZZINI, B.R.; ZÉTOLA, M.; BAZZO, G.C. Preparo e caracterização de micropartículas de acetobutirato de celulose e poli(3hidroxibutirato) contendo piroxicam. Acta Scient. Health Sci., v.31, n.1, p.51-56, 2009.

RITGER, P.L.; PEPPAS, N.A. A simple equation for description of solute release. II: Fickian and anomalous release from swellable devices. J. Control. Rel., v.5, p.37-42, 1987.

SAHU, A.K.; VERMA, A.; SINGH, S.K. Preparation of hydrophilic swelling controlled-release floating matrix tablets containing HPMC and chitosan. Int. J. Pharm. Pharm. Sci. v.4, n.1, p.82-87, 2012.

SCHAFFAZICK, S.R.; GUTERRES, S.S. Caracterização e estabilidade físico-química de sistemas poliméricos nanoparticulados para administração de fármacos. Quim. Nova, v.26, n.5, p.726-737, 2003.

SINGH, V.V.; BEHERA, B.; PRAMANIK, K.; PAL, K. Ultrasonication-assisted preparation and characterization of emulsions and emulsion gels for topical drug delivery. J. Pharm. Sci., v.104, n.3, p.1023-1044, 2015.

SOOTTITANTAWAT, A.; BIGEARD, F.; YOSHI, H.; FURUTA, T.; OHKAWARA, M.; LINKO, P. Influence of emulsion and powder size on the stability of encapsulated D-limonene by spray drying. Innov. Food Sci. Emerg. Technol., v.6, n.1, p.107-114, 2005.

SOOTTITANTAWAT, A.; YOSHII, H.; FURUTA, T.; OHKAWARA, M.; LINKO, P. Microencapsulation by spray drying: influence of emulsion size on the retention of volatile compounds. J. Food Sci., v.68, n.7, p.2256-2262, 2003.

STULZER, H.K.; TAGLIARI, M.P.; SILVA M.A.S.; LARANJEIRA M.C.M. Desenvolvimento, avaliação e caracterização físico-química de micropartículas constituídas de aciclovir/quitosana desenvolvidas pela técnica de spray-drying. Lat. Am. J. Pharm., v.26, p.866871, 2007. 
SUKSAEREE, J.; MONTON, C.; MADAKA, F.; CHUSUT, T.; SAINGAM, W.; PICHAYAKORN, W.; BOONME, P. Formulation, physicochemical characterization, and in vitro study of chitosan/ HPMC blends-based herbal blended patches. AAPS PharmSciTech, v.16, p.171-181, 2015.

UNITED STATES Pharmacopoeia: USP 30. Rockville: United States Pharmacopeial Convention, 2007.
WEARLEY, L.L.; ANTHONY, G.D. Metronidazole. Anal. Profiles Drug Subst., v.5, p.326-344, 1976.

Received for publication on $01^{\text {st }}$ November 2015 Accepted for publication on $24^{\text {th }}$ November 2016 